\title{
Maternidade transnacional e produção de subjetividade: as experiências de mulheres brasileiras imigrantes vivendo em Londres*
}

\author{
Manoela Carpenedo** \\ Henrique Nardi $* * *$
}

\section{Resumo}

Este estudo explora como a maternidade transnacional é experenciada por mulheres brasileiras emigrantes participantes da cadeia global dos cuidados. Nossa análise indica que a maternidade transnacional é uma experiência contraditória $e$ repleta de tensões emocionais. Por um lado, é vivida de forma culpabilizada por muitas mulheres por não se conformarem às regras da maternidade convencional. Por ouro lado, é por meio da experiência migratória que são capazes de renegociar seus papéis de mãe, produzindo novos sentidos para o cuidado e suas práticas maternas.

Palavras-chave: Maternidade, Maternidade Transnacional, Cadeia Global dos Cuidados, Subjetividade.

\footnotetext{
" Recebido para publicação em 3 de junho de 2016, aceito em 6 de setembro de 2016.

** Doutoranda no departamento de sociologia, Universidade de Cambridge, Reino Unido.mc800@cam.ac.uk

*** Professor e Diretor do Instituto de Psicologia da Universidade Federal do Rio Grande do Sul.hcnardi@gmail.com
} 
Transnational Motherhood and the Production of Subjectivity:

Experiences of migrant Brazilian women living in London

\begin{abstract}
This study explores how transnational motherhood is experienced by a group of Brazilian women participating in the global care chain. Our analysis indicates that transnational motherhood is an experience ripe with contradictions and emotional constraints. On one hand, transnational motherhood can subjugate women for not conforming to conventional motherhood norms. On the other hand, the migratory experience allows women to (re)negotiate their maternal roles, producing new meanings for care and mothering practices.
\end{abstract}

Keywords: Motherhood, Transnational Motherhood, Global care Chains, Subjectivity. 


\section{Maternidade transnacional, suas complexidades e reconfigurações da(s) subjetividade(s)}

Como as literaturas sociológica e feminista nos informam, o fluxo migratório de mulheres oriundas de países em desenvolvimento para países industrializados responde a modulações específicas promovidas pela globalização (Hochschild, 2000; Rodrígues, 2007; Sassen, 2003, 2008). A emergência das denominadas cidades globais ${ }^{1}$ combinada ao desenvolvimento de novos circuitos globais de sobrevivência, estes em resposta à pobreza e à falta de oportunidades em países economicamente periféricos, gerou um fluxo migratório importante de mulheres para capitais de países industrializados (Sassen, 2008). Devido à crescente demanda dos setores de serviço - como cuidado e trabalho doméstico - nesses centros globais, mulheres oriundas de países periféricos com poucas oportunidades de mobilidade social encontrariam na migração e na entrada no mercado informal do trabalho reprodutivo ${ }^{2}$ nos países do Norte global uma saída possível para conseguir melhores condições de vida ali do que em seus países de origem.

No que tange às experiências de trabalho que sustentam a possibilidade de viver no exterior para a maioria dessas mulheres, o conceito de cadeias globais de cuidado (Hochschild, 2000) ilustra de modo eficaz as consequências dessa transferência internacional de trabalho doméstico e de cuidado impulsionada pela globalização. Mulheres imigrantes atenderiam as demandas crescentes no setor reprodutivo de países industrializados. Em contrapartida, o trabalho doméstico e de cuidados de suas próprias famílias - muitas vezes deixadas em seus países de origem - é delegado para outra mulher, geralmente parte de sua

1 Que acumulam ao longo das últimas décadas funções econômicas chaves para mercado global (Sassen, 2008).

$2 \mathrm{O}$ trabalho reprodutivo se refere ao conjunto de tarefas desempenhadas com o objetivo de sustentar o trabalho produtivo no âmbito da esfera privada. Entre esses trabalhos estariam todas as tarefas domésticas desenvolvidas na manutenção do espaço privado e a reprodução da vida e o cuidado. 
família estendida ou ainda uma mulher mais pobre que, por sua vez, pode contar com outra mulher ainda mais empobrecida para a realização do seu trabalho reprodutivo. A emergência dessas dinâmicas internacionais de transferência de cuidados promoveu novos circuitos de cuidado, afeição e suporte financeiro, as quais estabeleceram redes difusas em diferentes localidades $e$ modalidades, transcendendo as fronteiras nacionais (HondagneuSotelo; Ávila, 1997). Novas relações familiares que se constroem nessas redes são definidas contemporaneamente como maternidades transnacionais.

A literatura anglófona que se dedica a discutir as famílias transnacionais, principalmente em suas leituras feministas, sugere que o papel da mulher como provedora pode ser intensificado pela migração (Hondagneu-Sotelo, 2001; Raijman et al., 2003). Tal papel pode desafiar de forma importante as normas de gênero e o código moral que define o que é ser uma "boa" mãe. Mães transnacionais $^{3}$ não necessariamente abandonam suas responsabilidades de cuidado, mesmo com a separação geográfica de suas famílias (Parreñas, 2005; Horton, 2009; Dreby, 2010). Pelo contrário, mães transnacionais continuam a se sentir emocionalmente responsáveis pelas/os suas/eus filhas/os e apoiam suas famílias de origem não somente financeiramente, mas também se fazendo emocionalmente presentes na vida de suas crianças (Dreby, 2010; Madianou, 2012). Mesmo distantes de suas/eus filhas/os, essas mulheres respondem às expectativas de gênero relacionadas ao cuidado: enviando remessas de dinheiro, presentes (Horton, 2009; Parreñas, 2001, 2005) e, mais recentemente, usando tecnologias de comunicação em suas práticas de maternidade à distância (Madianou; Miller, 2011; Madianou, 2012). Portanto, como a literatura corrente sobre maternidade transnacional demonstra, a distância e a ausência

3 As mulheres desse estudo não se reduzem à categoria de mães transnacionais; suas vidas são muito mais diversas e complexas que essa simples denominação, mas como esse é o foco do estudo em questão, para fins de clareza e objetividade iremos nos referir às participantes dessa pesquisa como tal. 
física são compatíveis com a participação dessas mães nas vidas de suas/eus filhas/os. Assim, a proximidade não se constitui em um pré-requisito sine qua non para vida em família no contexto da maternidade transnacional, pois o cuidado pode ser praticado à distância (Erel, 2002; Madziva; Zontini, 2012).

Por outro lado, a maternidade transnacional é acompanhada por uma série de restrições emocionais, já que sentimentos de inadequação e sofrimento podem ser vivenciados. A literatura nesse campo argumenta que vergonha e desesperança são emoções recorrentes nas falas e trajetórias das pessoas que experienciam a maternidade transnacional (Raijman et al., 2003; Parreñas, 2005; Horton, 2009; Schmalzbauer, 2009). Nossa análise dos relatos e as experiências vividas no trabalho de campo, bem como os estudos de Parreñas (2005) com mulheres filipinas (nos EUA e com suas famílias nas Filipinas) e Dreby (2006) com mulheres latino-americanas (nos EUA) indicam que esses sentimentos são regulados por normas sociais que definem a "boa" maternidade no interior das relações de poder que configuram o regramento de gênero.

Contrastando com grande parte dos estudos sobre maternidade transnacional, não nos focaremos aqui somente nas dores dessas mães por obedecerem às normas da maternidade ideal. Acreditamos que para entendermos como a migração impacta em uma reconfiguração da subjetividade para essas mulheres e mães é necessário analisar em um primeiro momento a maternidade como um construto social para, assim, explorarmos os modos pelos quais elas se filiam a certos discursos sobre maternagem, os desafiam e/ou ainda os reinventam. Nesse ponto, é importante perceber que proximidade entre mãe e filha/o e/ou mesmo a ideia de cuidado materno se constituem elementos relativamente recentes na história da maternidade.

Historiadoras/es, feministas clássicas e feministas póscoloniais têm desnaturalizado o conceito de maternidade. Em seu trabalho extensivo e sólido, Ann Oakley $(1979,1980)$ desconstrói o argumento biológico acerca dos "instintos maternos" demonstrando como esses são em verdade construções 
socioculturais. A problematização histórica acerca da maternidade nos informa sobre as práticas de cuidado infantil ao longo dos tempos, as quais não necessariamente envolveriam as mães biológicas (Donzelot, 1979; Badinter, 1981; Smart, 1996). Amas de leite entre burgueses, filhas/os mais velhas/os cuidando de seus irmãs/os mais novas/os entre mulheres trabalhadoras pobres, abandono ou infanticídio, exemplificavam os cuidados infantis antes fim do século XVIII na Europa. É na modernidade tardia, com a separação entre o público e o privado que houve uma mudança nas formas de conceber a maternidade (Smart, 1996; Donzelot, 1979). É somente com a ascensão da família patriarcal burguesa que as mães biológicas passam a ter um papel importante na socialização e na educação de suas/eus filhas/os (Habermas, 2003). Consequentemente, a ideologia e os valores burgueses acerca da maternidade tiveram um impacto nas políticas de cuidado infantil, especialmente ao naturalizar os laços emocionais e físicos entre as crianças e suas mães biológicas, introduzindo, dessa maneira, a ideia de amor materno (Badinter,1981). Na esteira desses processos, os discursos médicos e psicológicos contribuíram para essas modificações do papel das mulheres em relação à maternidade, principalmente por estabelecerem parâmetros específicos de "boa" e "má" maternidade (Donzelot, 1979; Smart, 1996). É no contexto póssegunda guerra mundial, com a crescente influência dos discursos psicanalíticos, que o papel materno se torna central no desenvolvimento infantil saudável: proximidade e exclusividade da díade mãe-bebê se tornam elementos cruciais de uma "boa" maternidade.

Levando em consideração essa conjuntura, é importante notar que a proliferação de tais discursos e parâmetros acerca da maternidade ideal passa a conferir lugar de desvio, anormalidade e/ou estigma a certas modalidades de maternidade. Como leituras feministas pós-coloniais apontam, esses discursos tiveram um impacto especial em mães pobres que sempre tiveram que trabalhar para sustentar suas famílias, mães solteiras, mães negras $e$ indígenas, já que tais standards de maternidade baseados na 
ideologia burguesa e branca conferiram muitas vezes a essas mulheres um status de "mães de segunda categoria" (Collins, 1998; Andersen; Collins, 2012).

Essas hierarquias estabelecidas por processos sóciohistóricos têm um papel importante no que diz respeito às dinâmicas de maternidade vivenciadas atualmente pelas mães transnacionais. Como demonstraremos, essas normas acerca da maternidade impactam fortemente os modos pelas quais essas mulheres se reconhecem como mães.

As escolhas teóricas que guiam este estudo têm um papel importante no enfoque multifacetado que oferecemos para a temática da maternidade transnacional. Seguindo a perspectiva de estudos feministas pós-estruturalistas contemporâneos, nosso entendimento acerca dos debates em torno das noções de agência é principalmente inspirado na contribuição foucaultiana acerca dos processos de subjetivação e de formação do sujeito. Nesse entendimento, a subjetividade é o resultado de estruturas de saber/poder pensadas de forma contingente às resistências $e$ ao regramento interior aos modos de subjetivação. Nesse sentido, a subjetividade e a agência devem ser entendidas no interior de relações de poder ancoradas em discursos sociais normativos. Isso não implica que o sujeito que emerge em um contexto específico esteja irreversivelmente aprisionado pelos discursos sociais. Pelo contrário, essas mesmas relações permitem ao sujeito se constituir de maneira ética a partir do incremento das práticas de liberdade (Foucault, 1988 ,1983, 1997). Dessa forma, podemos dizer que o conjunto de possibilidades de renegociação com os discursos sociais normativos é dependente das dimensões culturais, históricas, sociais e/ou normas morais experienciadas pelo sujeito nos processos de socialização e pelas condições criadas em sua trajetória de vida quando se depara com novos diagramas de poder (como no caso da imigração), os quais permitem desnaturalizar, mesmo que parcialmente, uma vida préestabelecida regrada pelos códigos culturais que marcam sua posição específica no mundo (Foucault, 1988, 1983). 
Essa noção de agência (pensada de forma contingente às relações de poder) é necessária para compreendermos os diversos modos pelos quais as mulheres deste estudo são subjetivamente reposicionadas pelo evento migratório em relação às normas convencionais de maternidade. Portanto, o foco analítico é direcionado ao evento migratório, visto que é a partir do deslocamento de fronteiras que uma reflexão sobre a maternidade é produzida por essas mulheres. Neste contexto, o evento migratório é encarado como gerador de rearticulações subjetivas importantes, visto que incita momentos de "moral breakdown" (Zigon, 2007). Nesse processo de revisão de valores morais os sujeitos são forçados a refletirem sobre os seus posicionamentos no mundo, trabalhar sobre si mesmos para responder certos dilemas e problemas (Zigon, 2007). Assim, as experiências de maternidade transnacional que exploraremos remetem aos modos múltiplos e diversos pelos quais mulheres mães se relacionam ao código moral $e$ às normas da maternidade convencional, renegociando certos aspectos de suas identidades como mães.

A maternidade transnacional é um fenômeno social bastante complexo e emblemático de nossos tempos. Apesar de os fatores macrosociais e econômicos serem bastante importantes para entendermos o contexto migratório, acreditamos que a problemática da maternidade transnacional não pode ser analisada considerando-se somente os fatores socioeconômicos que motivam as mulheres a migrar e os custos e benefícios da migração para elas e suas famílias. Embora esses fatores sejam indispensáveis à análise, uma perspectiva economicista pode não contemplar elementos importantes.

Nesse debate, ressaltamos também as recentes críticas que desestabilizam as noções consolidadas sobre os fluxos migratórios ao eixo "Sul-Norte". Para muitas imigrantes transnacionais suas experiências migratórias não são somente marcadas pelos regimes opressivos e discriminatórios que modulam migrações transacionais com finalidades econômicas, já que o evento migratório pode desafiar (e muitas vezes até reverter) a posição de subordinação experenciada por mulheres migrantes (Carpenedo; 
Nardi, 2013). Além disso, para muitas imigrantes transnacionais as motivações para a migração não são restritas exclusivamente a "melhoria de vida" em seus países de origem, mas também podem ser sustentadas por um desejo de "aproveitar a vida" no país de destino - optando por uma diversificação de oportunidades sociais, de lazer e consumo, que antes do evento migratório não eram disponíveis (Togni, 2014). Conjuntamente, sublinhamos dentre essas motivações, a chance de conhecer o mundo ou ainda a possibilidade de conhecer um companheiro estrangeiro (Piscitelli, 2013).

Para irmos além do determinismo social corrente nesse tipo de investigação e obtermos uma análise multifacetada do fenômeno, incorporaremos uma ênfase nas experiências dessas mulheres, bem como suas narrativas biográficas. Como nosso marco teórico sugere, analisaremos não somente os discursos sobre a maternidade aos quais essas mulheres se filiam, resistem e/ou reinventam-se como mães, mas também problematizaremos as tradições de cuidado infantil que carregam de suas famílias de origem. Pois é somente analisando esse conjunto de elementos que poderemos compreender os modos pelos quais o evento migratório (re)subjetiva essas mulheres em suas trajetórias como mães.

\section{O fazer da pesquisa e o perfil das participantes}

Para explorar as experiências subjetivas vivenciadas por mães transnacionais conduzimos entrevistas semiestruturadas com 23 mulheres brasileiras, majoritariamente trabalhadoras no setor de cuidados e serviço domésticos em Londres. Apesar da impossibilidade de generalização de nossa análise, ela permite compreender os processos de reconfiguração identitária atravessados por mulheres-mães migrantes vivendo na cidade de Londres.

A maioria das mulheres entrevistadas é proveniente de cidades brasileiras de pequeno ou médio porte. Nesse contexto, destaca-se no grupo entrevistado a migração de mulheres 
originárias do Centro-Oeste brasileiro. É relativamente recente a migração de mulheres dessa região para Londres, uma vez que grande parte das informantes migrou entre 2004 e 2011. É considerável o número de mulheres brasileiras que residiam previamente em outros países europeus tais como Portugal, Itália e Espanha. O agravamento da crise econômica nesses países impulsionou a migração dessas mulheres para Londres, onde puderam ampliar suas possibilidades de emprego e renda devido ao menor impacto da crise europeia na economia inglesa. Em relação à raça/cor, a maioria das entrevistadas se autodeclarou branca. Poucas mulheres se identificaram como mulheres negras. Grande parte das mulheres desta pesquisa tem uma afiliação religiosa; na sua maioria são evangélicas de denominações pentecostais e neopentecostais, sendo relevante o número de católicas, praticantes e não praticantes. Essas mulheres trabalhavam previamente no Brasil, majoritariamente em ocupações feminilizadas, tais como vendedoras de lojas, atendentes na área de serviços e agentes de telemarketing. Um número significativo já trabalhava no setor de cuidados como babás e empregadas domésticas e/ou diaristas. A grande maioria delas ainda não domina a língua inglesa ou possui uma fluência mínima. Apesar de a maioria das entrevistadas ser divorciada e/ou solteira, algumas têm companheiros e namorados na cidade de Londres. É importante ressaltar que uma pequena minoria vive legalmente no Reino Unido; a situação irregular é a realidade da maior parte delas.

As entrevistas para esta pesquisa foram realizadas em cafés, parques e frequentemente nas casas dessas mulheres. Com a finalidade de construir um retrato que busca contemplar a diversidade desse grupo social, a perspectiva etnográfica foi incorporada neste estudo. Esse "olhar" etnográfico permitiu não somente explorarmos os principais redutos da comunidade brasileira em Londres, mas também proporcionou certa imersão na vida de nossas interlocutoras. Percorremos uma gama de estabelecimentos e serviços: restaurantes brasileiros, cafés, centros comunitários, igrejas brasileiras etc. Essa estratégia facilitou tanto a 
aproximação da população estudada, como proporcionou uma variação considerável nos perfis das mulheres.

Como já afirmado, as entrevistas feitas foram inspiradas na abordagem biográfica, utilizada tanto para construir os relatos das trajetórias de vida dessas mulheres - enfocando suas experiências e narrativas pessoais - quanto para explorar de forma detalhada os contextos socioculturais vividos antes e após a imigração.

Sabendo que a separação familiar é um tópico bastante sensível, a dimensão ética no fazer da pesquisa foi central neste estudo. Portanto, o processo de pesquisa não foi somente guiado pelos standards de pesquisa qualitativa, como privacidade, confidencialidade (os nomes são fictícios), respeito e não utilitarismo, mas também pelo exercício constante de reflexão ética, sensibilidade e cuidado, respeitando sempre a vontade dessas mulheres no que tange à partilha de seus relatos como também nossa presença em seus espaços de convivência.

\section{$\mathrm{O}$ recorte}

Nossa revisão do conjunto de pesquisas que se dedicam à migração brasileira no exterior indica que este estudo é o primeiro a abordar a problemática da maternidade transnacional . Além disso, o caso inglês é particularmente interessante. Apesar de o fluxo migratório de brasileiros para o Reino Unido ter aumentando desde os anos 2000, a presença brasileira ali não foi propriamente analisada e ainda é pouco teorizada (Kubal et al., 2011). É difícil obter dados precisos sobre a comunidade devido ao seu caráter irregular. É estimado que existam por volta de 150,000 a 200,000 brasileiras/os vivendo em Londres e 250,000 brasileiras/os em todo o Reino Unido, constituindo-se atualmente na maior comunidade brasileira na Europa (Kubal et al., 2011). Brasileiras/os vivendo no Reino Unido geralmente não possuem um status regular, documentado (Evans et al., 2007). Elas/es entram como turistas e acabam ficando no Reino Unido irregularmente.

Além disso, as particularidades da estrutura familiar brasileira têm efeitos nas reconfigurações da maternidade 
transnacional. Apesar de ainda carregar marcas dos valores coloniais da familiar nuclear patriarcal, especialmente enrijecida pela influência da Igreja Católica (Therborn, 2004), os modelos baseados no colonialismo europeu foram frequentemente confrontados por outros arranjos familiares. A organização familiar na classe trabalhadora sempre assumiu uma multiplicidade de formas, sendo incontáveis famílias chefiadas por mulheres. Nesses contextos, redes de solidariedade em que crianças são cuidadas por membros da família estendida e vizinhos enquanto suas mães estão trabalhando sempre foram bastante usuais (Fonseca, 2005). Essas particularidades das dinâmicas e das formas de entender a vida familiar podem não somente facilitar a migração, mas também, como veremos, dar outros contornos aos efeitos da separação geográfica para essas mães brasileiras vivendo em Londres.

\section{Os contextos de migração}

Os custos e benefícios da maternidade transnacional não podem ser entendidos de forma única ou fixa, já que existem negociações que variam de acordo com os contextos sociais dessas mulheres em seus países de origem (Suárez-Orozco, 2009).

Refletindo as consequências sociais da globalização e da feminilização do mercado de trabalho (Hirata, 2006), as participantes deste estudo têm trajetórias de trabalho marcadas por empregos vulneráveis e precários. Previamente inseridas em ocupações feminilizadas, seus empregos eram instáveis, mal remunerados e pouco valorizados socialmente. É importante lembrar que além de gênero e classe social, outros marcadores que regulam o mercado de trabalho tais como raça/cor também restringiram as possibilidades de crescimento profissional no Brasil de muitas dessas mulheres.

Essa falta de perspectiva de crescimento era incrementada por outros fatores estruturais. Participantes de uma tendência tanto dos países do Norte como do Sul (Hirata, 2006), muitas informantes desta pesquisa são as principais responsáveis 
financeiras por suas famílias. Portanto, o papel de provedora familiar foi sempre presente na vida dessas mães chefes de família. Assim, a responsabilidade econômica pela vida de suas famílias não surgiu pós-migração; pelo contrário, suas identidades maternas sempre foram caracterizadas por esse imperativo. Em sua maioria, elas são as únicas responsáveis pelo sustento de suas/eus filhas/os. A ausência de ajuda financeira dos pais de suas crianças contribui fortemente para os sentimentos de preocupação e responsabilidade em serem capazes de garantir a sobrevivência de suas/eus filhas/os. Mesmo as mulheres que ainda viviam com os companheiros/pais de seus filhos, sempre trabalharam para garantir o bem-estar de suas famílias. Sendo assim, o trabalho na vida dessas mulheres sempre esteve bastante presente $e$ foi negociado em conjunto com as suas identidades maternas. A figura de mães guerreiras foi bastante invocada por várias participantes. São mães que se definem como trabalhadeiras e que usam esse imperativo como motor para superar os obstáculos da vida, para garantir o sustento e uma vida melhor para suas/eus filhas/os.

Podemos dizer que o papel de provedoras de suas famílias foi intensificado com a migração. Assim, a saída migratória é, para essas mulheres com possibilidades restritas de acesso a bens de consumo e simbólicos, um modo de viabilizar seus desejos $e$ vontades de forma a ter uma ocupação com melhores ganhos financeiros (Togni, 2014). Portanto, é por meio do evento migratório que essas mulheres são capazes de potencialmente reverter o ciclo de reprodução da pobreza em suas vidas e na vida de suas famílias.

Nesse ponto, é importante problematizar as noções fixas sobre vulnerabilidade e precariedade. Tais noções não devem ser essencializadas, já que é pertinente questionar como certos atributos como (gênero, idade, classe social e nacionalidade) podem se tornar marcadores privilegiados de passividade $e$, consequentemente, de vitimização (Lowenkron, 2015). Essa crítica é bastante pertinente para a categoria das mulheres empobrecidas chefes de família oriundas de países em desenvolvimento, que 
muitas vezes é utilizada de forma monolítica nos estudos sobre a feminilização das migrações transnacionais. De fato, não é possível prever ou generalizar os fatores de vulnerabilidade imbricados na migração dessas mulheres. É certo que alguns corpos ou coletivos podem ser mais vulnerabilizados e precarizados que outros (Butler, 2006), devido a circunstâncias históricas ou situacionais, muitas vezes conectadas à falta de redes de apoio sociais e econômicas (Butler, 2010, apud Lowenkron, 2016). Mas é importante lembrar que as dimensões de vulnerabilidade e precariedades são intrínsecas a todos os corpos (Butler, 2006).

Como Lowenkron (2015) sugere, é pertinente desestabilizar o foco dos atributos individuais para a dimensão relacional das dinâmicas de vulnerabilidade e precariedade. Determinados atributos (tais como gênero, classe, nacionalidade e raça) adquirem sentido somente em contextos sociais e relacionais específicos (Lowenkron 2015). Portanto, o contexto social e os suportes materiais, simbólicos e institucionais não podem ser tomados como fatores per se nas vulnerabilidades associadas a situações de migração irregular. Tais vulnerabilidades devem também ser entendidas tanto como o resultado de políticas migratórias repressivas, quanto da ausência ou do enfraquecimento de redes de apoio econômico e social (Lowenkron, 2015:246).

Sendo assim, apesar de considerarmos a dimensão econômica de "melhorar de vida" presente na narrativa sobre as motivações migratórias dessas mulheres, desafiamos, ao mesmo tempo, as visões essencializadas que promovem a fixação da precariedade e da vulnerabilidade em suas vidas. Dessa maneira, propomos uma compreensão multifacetada do evento migratório na vida das participantes deste estudo.

\section{O peso da separação geográfica na subjetividade das mães transnacionais}

De forma coerente com a perspectiva teórica utilizada, entendemos que a maternidade é intensivamente regulada $e$ 
controlada por uma série de discursos normativos que produzem modos inteligíveis e socialmente aceitos de ser mãe, os quais encontram uma síntese no ditado "mãe é tudo igual" (Moreira; Nardi, 2009). Entre a multiplicidade de discursos que a regulam na contemporaneidade, a problemática da proximidade da díade mãe e criança é central (Parreñas, 2005; Madianou, 2012).

Para as participantes desta pesquisa, o ideal de proximidade física e de contato face a face com suas/seus filhas/os não está presente em seus repertórios como mães. No entanto, a norma de proximidade física influencia fortemente os modos pelos quais elas se reconhecem como mães. Por não se conformarem aos ideais de maternidade, muitas das mulheres entrevistadas expressaram sentimentos de sofrimento, culpa e perda. Algumas se sentem bastante inadequadas e até duvidam de seus papéis de mães. Flávia fala um pouco sobre os seus sentimentos:

Flávia: É o meu sonho ter outro filho e ser uma mãe de verdade. Algumas pessoas me perguntam: Mas você já não é mãe? E eu respondo: Não, eu não sou mãe 100\%. Como eu disse, quando o meu filho precisou de mim eu estava fora. Eu tive que deixar ele. E eu sempre vou ter essa culpa nos meus ombros.

Manoela: Então tu não te vês como mãe, Flávia?

Flávia: Não, eu não me vejo. Meu filho me chama de mãe de maminha, mas eu me sinto muito culpada por não estar lá para ele. Às vezes, eu me pergunto por que eu deixei ele. Mas eu tinha que vir, eu não tinha nenhum dinheiro. Mas quando ele precisou de mim, eu não estava lá! Eu perdi a oportunidade de ver o meu filho crescer!

O relato de Flávia remete às dores e aos sofrimentos enfrentados por muitas das participantes deste estudo. Proximidade e presença se constituem em um elemento importante, quiçá definidor de maternidade para algumas. $\mathrm{O}$ reconhecimento e a aceitação dos ideais de proximidade física com suas/eus filhas/os resultam em uma desqualificação de algumas modalidades de cuidado e maternidade transnacional. 
Apesar de poucas, algumas das entrevistadas como Flávia não conseguiram se deslocar subjetivamente da norma de proximidade em relação aos suas/eus filhas/os $e$, consequentemente, se reconhecem como mães que falharam em seu papel materno justamente por estarem longe. Sendo assim, sentem-se inadequadas justamente por não se conformarem às expectativas de maternidade e de gênero nelas depositadas.

Essa postura colada aos discursos contemporâneos de "boa maternidade" gera identidades maternas caracterizadas pela melancolia. Em muitos casos, esses sentimentos de culpa e dor por serem mães à distância as legitimam como mães nessa identidade culpada de "mães melancólicas". É nessa posição melancólica de sofrimento subjetivo que suas expressões de amor materno podem existir.

Para mim todo domingo é um dia muito triste. Porque era domingo que eu ficava com a minha filha e a gente comprava chocolate e comia junto (...) Isso mesmo já estando 9 anos aqui (...) todo sábado eu compro o meu chocolate e como sozinha me lembrando da minha filha (Anita).

A separação da família é frequentemente vista como irremediável em perspectivas psicológicas. Muitas entrevistadas mencionaram em suas narrativas discursos médicos e psicológicos que conectam a proximidade materna ao bom desenvolvimento infantil. Dessa forma, referem-se a sentimentos de culpa por suas performances "insuficientes" como mães quando suas/eus filhas/os apresentam problemas como perda de peso, depressão $e$ experimentação com drogas.

Esses sentimentos de inadequação referidos pelas entrevistadas são usualmente acompanhados por uma posição de abnegação. Assim, na lógica da autopunição, para preservar suas identidades como mães, elas, que não conseguem estar presentes no dia a dia das crianças, acreditam que devem sofrer enquanto trabalham para o bem-estar dessas mesmas crianças. Portanto, 
como muitas participantes deste estudo afirmam, uma característica importante de uma boa mãe transnacional é o autossacrifício. A norma da figura materna como sendo naturalmente abnegada foi constantemente reproduzida em suas narrativas. Sendo assim, essas mulheres seriam figuras protetivas que estariam sujeitas a todo tipo de sacrifício em função do bemestar maior de suas/eus filhas/os.

Quando você é mãe de verdade você tem que botar o seu filho em primeiro lugar. As mães que dizem que não mudou nada na vida delas, não são boas mães, não. Tudo que eu faço é para o meu filho (Marli).

Esse posicionamento de mãe mártir emergiu frequentemente na narrativa das participantes. ${ }^{4}$ Tal identidade pode ser vista como uma estratégia para negociar com a distância, com as normas que definem uma boa maternidade e com seus papéis de provedoras, visto que essas mães justificam essa posição de abnegação e sacrifício ao assumirem o papel de responsáveis financeiras de suas famílias. Portanto, é nessa posição de mártir que muitas dessas mulheres conseguem negociar suas identidades maternas no contexto da situação transnacional.

Essa posição de mártir reafirma a norma de gênero, naturalizando a maternidade abnegada e o papel cuidador feminino. As negociações com a norma da maternidade, no caso de algumas mães deste estudo, reforçaram identidades afirmadas em torno da noção de abnegação. Apesar de desafiarem o mandato da proximidade física através da modalidade transnacional de suas maternidades, essas mães acabam se colando a um ideal materno sacrificial. Tal posicionamento reproduz e reedita as expectativas $e$ as normas de gênero que regulam a performatividade feminina, ao reiterar um ideal de maternidade. Percebemos nesses posicionamentos, de que forma

4 Parreñas (2001) em seu estudo com filipinas vivendo nos EUA encontrou lógicas identitárias similares. 
os sujeitos são subjetivados pela experiência de maternidade transnacional. Muitas vezes, a reflexão e o consequente reposicionamento moral motivado pelo evento migratório são feitos de forma a reiterar as normas de gênero que regulam a "boa" maternidade.

Esses sentimentos de sacrifício, culpa $e$ inadequação são reforçados consideravelmente pelas características das ocupações laborais das participantes desta pesquisa. Algumas delas trabalham como babás e/ou trabalhadoras de cuidado. Sendo assim, as atividades cotidianas dessas mulheres envolvem uma dimensão emocional importante, visto que muitas têm que cuidar das crianças de suas/eus empregadoras/es. O trabalho emocional desempenhado tem efeitos importantes em suas identidades maternas.

De acordo com elas, é muito difícil negociar a dimensão emocional de suas ocupações já que, além do trabalho de cuidar ser bastante demandante emocionalmente, ele pode produzir sentimentos confusos em relação às crianças que cuidam em Londres. Muitas afirmam que o trabalho necessita de uma conexão verdadeira com as crianças $e$ isso acaba sendo muito difícil negociar.

O meu trabalho é puro amor. Eu amo as crianças que eu cuido. Eu sei que não são minhas, mas é como se fosse (...) Sou eu que passo mais tempo com elas (...) E nem se compara com o tempo que eu passo com o meu filho (...) É muito sofrido isso (Roberta).

Eu me sinto muito culpada porque eu trabalho cuidando de criança. Eu converso com elas, abraço, beijo ... e elas também me beijam (...) Mas quando eu penso que eu não tenho isso com os meus filhos, é horrível (...) Tem dias que estou muito triste e choro no trabalho. Mas a minha patroa nem quer sabe da minha vida. Eles querem você bem, sorrindo no trabalho, brincando com as crianças (Silvana).

Como podemos perceber, as emoções não são somente parte do repertório dessas mulheres como trabalhadoras, mas 
também constitui-se em uma fonte de sofrimento e stress, já que a dor causada pela ausência de suas/eus filhas/os pode ser intensificada por suas experiências de trabalho. Nesses casos, as características de suas ocupações laborais amplificam a dor e os sentimentos de inadequação como mães por não se adequarem às normas que regulam não somente a maternidade, mas também o gênero.

Negociações e sacrifícios: "Tudo tem um preço"

A maternidade transnacional implica uma constante negociação entre sacrifícios e glórias. De fato, por meio da saída migratória, muitas dessas mães conseguiram garantir não somente o sustento de suas famílias, mas também asseguraram melhores condições educacionais e de saúde. Esses elementos mitigam em certa medida os sentimentos de inadequação $e$ sofrimento causados pela distância. Pudemos observar que muitas dessas mães associam o cuidado materno ao sustento de seus lares. Assim, essas mulheres não se sentem somente boas cuidadoras por manterem financeiramente suas famílias no Brasil, mas também desenvolvem uma melhor autoimagem como mães. Além disso, as remessas de dinheiro são também vistas como uma forma de se manter em contato e interagir com suas/eus filhas/os.

Tudo o que eu fiz foi para dar um futuro melhor para as minhas meninas. Quando eu visitei elas, a minha mais nova me perguntou por que ela estava vivendo com a avó e não comigo (...) Eu disse que eu deixei ela porque eu precisava de dinheiro para dar de comer para ela. (...) E as pessoas na rua dizem que eu sou fraca que eu não sou uma boa mãe. Que eu abandonei as minhas filhas. Pode ser, eu posso ser fraca, mas eu prefiro ser fraca $e$ ver as minhas filhas crescendo em uma situação melhor do que ter elas no meu lado passando fome (Carla).

É interessante perceber os modos pelos quais essas mães redefinem a maternidade a partir de suas experiências. A 
modalidade transnacional representa uma negociação no interior de uma rede discursiva que define a maternidade. Ao desafiar a norma da proximidade entre mãe e suas/eus filhas/os, essa modalidade inaugura outras possibilidades de ser mãe, como por exemplo, a de ser provedora financeira da família. Ao definir uma boa maternidade em termos de cuidado financeiro, essas mulheres ganham legitimidade como mães. Dessa forma, percebemos como o evento migratório pôde reposicioná-las em relação às normas convencionais de maternidade, visto que elas não somente foram capazes de trabalhar sobre si mesmas respondendo aos dilemas relacionados à maternidade transnacional, como também (re)negociaram de forma eficiente suas identidades maternas. Por meio dessas negociações, elas são capazes de desestabilizar as normas correntes de boa maternidade, além de engendrarem mudanças estruturais na família, muitas vezes como provedoras principais. Muitas dessas mulheres afirmam o sentimento de empoderamento com a experiência migratória, especialmente pela seguridade financeira adquirida para a família e muitas vezes para a família estendida.

As narrativas ressaltam que suas/eus filhas/os agora podem desfrutar de oportunidades melhores, como escolas privadas, planos de saúde e aulas de inglês. Além disso, muitas entrevistadas sustentam parte de suas famílias estendidas (seus pais, irmãs), arcando com custos de saúde e alimentação. Algumas já compraram casas em suas cidades de origem, outras ainda juntam dinheiro para construir seus próprios negócios no Brasil. Dessa maneira, podemos ver a constante negociação promovida pelo evento migratório em suas vidas. Por um lado, essas mulheres se sentem oprimidas pela ausência física. Por outro, são capazes de negociar certos espaços ao confrontar não somente os contextos sociais e econômicos em seu país de origem, mas também por relativizar o mandato social de proximidade entre mãe e suas/eus filhas/os, consequentemente definindo em outros termos cuidado materno e suas identidades como mães. 
Com a distância você muda muito como mãe. Esse sentimento de querer ficar do lado do seu filho e não poder. É muito difícil. Mas tudo o que eu fiz, eu fiz foi por ele, pra ele ter um futuro melhor. Dar uma escola boa para ele pra poder ser alguém na vida. Pra você ter alguma coisa nessa vida tem que passar por dificuldade. Tudo tem um preço. Esse é o meu preço, ter que ficar longe de meu filho. Por ter sido mãe solteira. O preço é alto, mas vale a pena porque eu tenho os meus objetivos. Senão tivesse, eu seria uma boba. Eu não pagaria esse preço, não. Mas na vida tudo tem um preço, Manoela. Eu estou aqui pagando o meu (Luana).

Mães transnacionais não podem ser entendidas de forma estática e monolítica - somente como vítimas da globalização, da pobreza, da violência de seus contextos. As narrativas dessas mulheres revelam como elas são capazes de articular sua agência em contextos pouco favoráveis, modificando não somente as suas vidas, mas a vida de suas famílias. Certamente, os espaços possíveis de reinvenção são limitados pelas dinâmicas socioeconômicas e pela rede discursiva que busca fixar suas posições como mães e mulheres. No entanto, como apontam os relatos, essas mães ainda encontram espaços para negociar suas identidades maternas, redefinindo nesse processo os modelos $e$ introduzindo novas modalidades de cuidado $e$ afeto.

\section{Redes de cuidado e solidariedade}

A separação familiar não pode ser entendida como um evento traumático per se, especialmente em culturas familiares que se distanciam dos modelos que regulam a maternidade contemporânea. Embora a separação familiar seja normalmente narrada como sendo muito difícil e emocionalmente desgastante, o nível de preparação da criança, a intimidade e a confiança entre criança e suas cuidadoras substitutivas, além das tradições de cuidado infantil em suas famílias de origem, têm um papel importante no processo de separação. Nesse contexto, as redes 
familiares de suporte constituem um fator crucial para entendermos as dinâmicas de cuidado em famílias transnacionais.

As participantes afirmam que sem o suporte e o apoio de suas famílias estendidas sua migração seria impossível. Suas/eus filhas/os são cuidados por membros de sua própria família (majoritariamente mães e irmãs) ou por membros da família do pai de suas crianças. Contrastando com a literatura sobre maternidade transnacional (Parreñas, 2005; Horton, 2009), muitas das mulheres entrevistadas já tinham redes de apoio e cuidado antes do evento migratório. Como sempre tiveram que trabalhar, grande parte dessas mulheres já confiava à sua família ou à família dos pais de suas crianças o cuidado de suas/eus filhas/os durante suas horas de trabalho. Sendo assim, elas já dispunham previamente de uma rede forte de suporte e cuidados. Essas redes demostram os modos pelos quais essas mulheres já lidavam de forma coletiva e solidária com seus contextos sociais. Essas mães afirmam que não teriam migrado se não confiassem nas cuidadoras substitutivas de suas/eus filhas/os. De forma geral, elas se sentem seguras em relação à educação, ao cuidado e à gestão do dinheiro de suas remessas.

Minha mãe toma conta do meu filho. Eu confio nela $100 \%$ (...) O pai dele nunca quis saber dele (Luana).

Minha mãe morreu 3 anos atrás. Antes era ela que cuidava ele. Agora é a minha irmã mais velha que cuida dele com o dinheiro que eu mando (Rita).

Eu não podia deixar o meu filho com a minha mãe porque ela é alcoólatra. A outra avó quis ficar com ele.(...) Ela gosta muito do menino; já o pai não ajuda com nada (Flávia).

É interessante notar que todas as cuidadoras substitutivas dessas mães são mulheres também. Em nenhum dos contextos a criança é cuidada pelo pai. Nos casos em que a família paterna se envolve com a criança, ela é cuidada somente pela avó e, em alguns casos, avó e avô. Portanto, percebemos claramente que 
uma modulação de gênero regula essas redes de apoio e cuidado. Essa característica nos indica que novamente as normas de gênero que reforçam o papel cuidador feminino organizam as modalidades de cuidado, mesmo em contextos transnacionais.

Para compreendermos as dinâmicas que envolvem as famílias transnacionais, é importante em primeiro lugar analisarmos as tradições de cuidado das crianças nas famílias de origem dessas mulheres. Nessa direção, é imprescindivel reconstruirmos as trajetórias dessas mães como filhas, já que suas biografias podem nos auxiliar a compreender os elementos que as levaram a deixar suas crianças sob os cuidados de suas famílias estendidas.

No contexto analisado, é importante notar que algumas das mulheres desta pesquisa não experenciaram em suas próprias infâncias o modelo de proximidade entre mãe e filha. Muitas das entrevistadas circularam em sua infância entre membros de suas famílias estendidas - avós, tias - e, em alguns casos, foram criadas por madrinhas. Essas dinâmicas de "circulação de crianças" entre cuidadoras substitutas em famílias de grupos populares foram extensivamente analisadas por Claudia Fonseca (1998). Em seus estudos, a antropóloga analisa essas práticas de cuidado que emergem muitas vezes para facilitar $e$ viabilizar mães trabalhadoras e chefes de família.

Relatos de "circulação de crianças" entre as participantes deste estudo são bastante comuns, $e$ indica que elas mesmas experenciaram em suas vidas figuras outras de cuidado e afeto não restritas às suas mães biológicas.

Quando eu tinha 5 anos, minha mãe me levou de casa para viver com a minha avó, que não é minha vó, mãe da minha mãe, mas é a madrinha da minha mãe. Ela que criou a minha mãe porque a minha vó de verdade não tinha condições de criar minha mãe sozinha. Minha mãe e minha tia foram criadas por ela. (...) Minha madrinha estava velha e sozinha e minha mãe decidiu me dar para ela. Minha irmã mais nova tinha recém-nascido e minha mãe queria se mudar para outra cidade e eu não queria me 
mudar. Então eu fiquei com a madrinha. (...) Eu via a minha família todo fim de semana, eles me visitavam. Eu vivi com a madrinha dos 5 até os 13. Quando ela (a madrinha) morreu, eu voltei pra minha família (...) Eu tive uma infância ótima. (...) Eu tinha duas mães (Salete).

Eu cresci dividida entre a casa da minha família e a casa da minha tia. Quando eu era pequena, eu vivia com a minha mãe e meus irmãos, mas, quando eu tinha uns 9 anos, eu fui morar na casa da minha tia. Eu morava lá para poder ficar com as minhas primas e a minha escola era mais perto também. Eu vivi lá por 7 anos. Eu adorava, eu tinha duas casas! Todo o sábado minha mãe me ligava: minha filha, você não vem passar o final de semana com sua mãe, não? E eu ia pra casa. (...) Minhas primas são até hoje como minhas irmãs (Juliana).

Eu e minha mãe morávamos na casa da minha tia quando eu era pequena. Aí... minha tia me mimava tanto, era uma criança muito mimada. Mas era muito feliz. Por uns anos, minha mãe não vivia com a gente, vivia com o meu padrasto. Depois, mais tarde, eu mudei com eles, mas o meu tio do interior também foi morar com a gente. Ele era mais novo, ele que cuidava da gente quando a minha mãe saía para trabalhar (Lisa).

Nessas narrativas, percebemos o modo pelo qual essas mulheres descrevem suas experiências de crescer entre múltiplas/os cuidadoras/res. Essas vivências certamente impactam as formas pelas quais essas mães definem cuidado e seu papel materno. Como vemos, o cuidado em seus contextos de origem não é necessariamente desenvolvido por uma cuidadora central (a mãe biológica, por exemplo). Ao contrário, laços afetivos $e$ responsabilidades de cuidado são distribuídos entre atrizes sociais distintas, as quais são parte desse elenco plural de cuidadoras/res.

Esses exemplos desestabilizam não somente o modelo de família nuclear burguesa, mas também os sentidos correntes de cuidado e papel materno. Talvez até por terem experienciado essa 
"circulação" nas tradições de cuidado infantil em suas famílias de origem, essas mulheres se autorizaram a lançar-se à migração, desafiando as normas correntes de maternidade ao incluírem-se nas dinâmicas de solidariedade e reciprocidade encontradas nessas redes de cuidado. É interessante perceber que nessas dinâmicas elas não possuem um papel fixo. Lisa comenta entusiasmadamente sobre o seu futuro e seu desejo de ter a sua "vez" como cuidadora.

No meu futuro, me vejo na minha casa com jardim, cuidando das minhas netas. Eu tenho essa impressão que eu vou ser avó bem cedo porque a minha pequena é terrível, ela é que nem eu! Eu vou ser avó bem cedo (risos). Assim eu vou poder ser mãe de novo! (Lisa).

Vemos que as noções de maternidade, cuidado e papel materno estão sujeitas a contextos culturais e podem assumir outras nuances. Essa evidência nos informa da importância de levarmos em consideração as narrativas biográficas de mães transnacionais quando avaliamos os efeitos da maternidade transnacional em suas vidas, visto que suas narrativas indicam a existência de múltiplos sentidos e negociações possíveis em relação à maternidade. Ao confrontar as normas disciplinares que regulam a maternidade por meio da solidariedade $e$ da reciprocidade, essas mulheres são capazes não só de enfrentar suas realidades pouco favoráveis, mas também de reinventar novos sentidos para o cuidado e a identidade materna. Portanto, percebemos os modos pelos quais essas mulheres se reposicionam em relação às normas da maternidade convencional. À medida que invocam suas próprias experiências plurais de serem cuidadas, elas revelam os modos múltiplos e diversos pelos quais essas mães se relacionam ao código moral $e$ às normas da maternidade convencional. 
Sendo uma mãe presente à distância: o papel da tecnologia

Contato regular e qualidade nas interações têm um papel muito importante nas práticas de cuidado entre mães transnacionais (Parreñas, 2005; Zentgraf; Chinchilla, 2012). A comunicação com suas famílias minimiza os custos da separação $e$ as auxilia a lidar com os sentimentos de aflição, culpa $e$ tristeza/solidão. Ao incorporar tecnologia e engenhosidade em suas práticas diárias de resistência, essas mulheres reinventam modos de cuidado materno.

Essas mães experienciando a maternidade à distância usam várias tecnologias disponíveis para estarem perto de suas/eus filhas/os em suas rotinas. Entre elas, destacamos: ligações telefônicas, mensagens de texto de celular, interações com vídeocâmera (Skype). Segundo elas, o uso dessas tecnologias é indispensável tanto para o seu bem-estar emocional, como para acompanharem o desenvolvimento de suas/eus filhas/os. Essas sessões permitem a essas mães estarem presentes na rotina de suas crianças. A maior parte das participantes diz falar diariamente com suas/eus filhas/os, outras pelo menos uma vez por semana. Muitas têm acesso à internet em suas casas com seus computadores ou mesmo em seus telefones; algumas vão a internet cafés ou usam cartões telefônicos. Membros de suas famílias no Brasil também aprenderam a lidar com as novas tecnologias. Quando mais idosos, mães e pais geralmente são assistidos por um membro mais novo de suas famílias estendidas, que faz um papel de mediadora/o tecnológico.

Mães de crianças mais novas preferem as interações de vídeo-câmera, pois como uma delas afirma "por telefone é difícil falar com a pequena, eles precisam ver você, sabe?" A copresença virtual inaugura para essas mães a possibilidade de ter momentos íntimos com suas/eus filhas/os, conseguindo ter uma experiência mais próxima de cuidado, segundo elas. A modalidade de cuidado torna efetiva a maternidade quando uma mãe toma conta de suas/eus filhas/o nessas interações virtuais, nas quais imagem, olhar e som produzem uma conexão capaz de 
reunir mães e filhas/os novamente. Natália fala de suas visitas online:

Lá em casa, eles compraram essas TVs grandes, sabe? E meu tio instalou uma coisa pra conectar a TV com o computador (...) Todo domingo nos falamos pelo Skype e eles me botam lá na TV grande. Minha caçula adora quando fazem isso! Ela diz que adora quando eu estou grande (...) Eu me sinto como se estivesse lá, enchendo toda sala na TV (Natália).

Outras estratégias engenhosas para estarem perto de suas/eus filhas/os também foram citadas. O uso de plataformas como email, Facebook e Whatsapp foi bastante comentado como recurso de mandar textos e fotos. Por meio dessas plataformas, essas mães são capazes não somente de interagir com suas famílias, com as professoras de suas/eus filhas/os, mas também podem escolher as roupas delas/es, ajudar na lição de casa etc. Tudo é feito online. Salete comenta como uma atividade comum entre mãe e filha pré-adolescente pode ser realizada por meio do uso dessas tecnologias.

Eu adoro comprar presentes para a minha filha. Eu geralmente vou para a loja, dou uma olhada nas coisas $e$ tiro umas fotos de roupas que ela gostaria. Depois eu mando por whatsapp para ela escolher.(...) Ela olha $e$ decide o que quer, depois eu mando os presentes pelo correio (Salete).

No relato de Salete, vemos como objetos, fotos, intenção e interação virtual podem emergir, em contextos transnacionais, como uma prática vívida de carinho e cuidado. Dessa forma, por meio de muita criatividade e o uso das tecnologias, essas mães negociam diariamente práticas de resistência de forma a relacionarem-se melhor com as normas de maternidade, preservando assim, por meio dessas práticas, suas identidades como mães. Essas práticas permitem a essas mulheres se sentirem 
empoderadas, já que passam, em certa medida, a controlar e a acompanhar o crescimento de suas/eus filhas/os.

Não há dúvidas que essas mães podem estar ativamente presentes nas vidas de suas/eus filhas/os. Mesmo com a distância, muitas delas conseguem assegurar não somente sua identidade materna, mas também sua autoridade como mãe. Mesmo longe, muitas dessas mulheres avaliam o comportamento de suas/eus filhas/os, julgam seus atos e aplicam punições. Juliana fala como controla o comportamento de seu filho de 6 anos.

Meu filho nunca escapou dos meus castigos mesmo de longe. Minha mãe e minha irmã me contam sempre quando Eduardo se comportou mal (...) e eu não me sinto culpada, eu dou castigo nele mesmo de longe. Eu falo com ele, brigo e a minha mãe ou irmã castigam. (...) Eu sei de tudo, mesmo de longe. Eu sinto, sabe? Como mãe a gente sente! Quando eu sinto, pergunto logo à minha irmã e ela fala quando ele se comportou mal.(...) Eu peço para falar com ele. E sabe que ele faz quando se comporta mal? Ele não quer falar comigo pela câmera. (...) A minha mãe chama: "Eduardo, venha cá, venha falar com a sua mãe". E ele responde, "Não vó não vou não estou jogando bola com o João" (...) Isso me deixa louca. Ele faz isso porque ele tem medo de falar comigo porque ele sabe que tem castigo! (...) Quando isso acontece, a minha mãe força ele a falar comigo. Ele me fala e depois eu dou castigo para ele (Juliana).

A narrativa de Juliana ilustra claramente as complexidades de exercer a autoridade materna à distância. Apesar de ter a sua autoridade preservada, não sabemos de que forma o castigo é exercido pela família estendida. De fato, essas mulheres são extremamente dependentes da ajuda das cuidadoras substitutivas de suas/eus filhas/os, responsáveis pelo cuidado e educação, e também são quem mediam a comunicação entre mãe de suas/eus filhas/os. Muitas mães reclamam, por exemplo, da falta de transparência por parte de suas famílias estendidas, principalmente 
em relação a doenças ou acidentes com suas/eus filhas/os. As tentativas das famílias em preservar e não incomodar essas mães são geralmente interpretadas de modo negativo, já que, assim, elas sempre têm que ler nas entrelinhas para saber o que de fato está acontecendo. Segundo elas, esse jogo de adivinhação é muito ansiogênico e prejudicial para suas práticas de cuidado à distância.

Apesar desses percalços, é importante frisar que, por meio do uso da tecnologia, essas mulheres brasileiras são capazes de incluir em seu repertório práticas diárias de resistência, capazes de desafiar as fronteiras contemporâneas da norma referente à maternidade. A intensa presença online na vida de suas/eus filhas/os inaugura na vida dessas mulheres um sentido de pertença social e familiar mesmo à distância. Portanto, o uso dessas tecnologias modifica o modo como essas mulheres se subjetivam como mães.

É importante notar que o fato estarem constantemente em contato com suas famílias estendidas acaba renovando suas expectativas e obrigações como mães. Como Parreñas (2005) observa, mães transnacionais não perdem suas obrigações emocionais para com suas/eus filhas/os. Ao contrário, elas desempenham suas obrigações maternas à distância, em paralelo com sua função de provedoras. Portanto, mesmo geograficamente distantes, essas mulheres respondem às expectativas sociais de serem as cuidadoras de suas/eus filhas/os. Sendo assim, podemos concluir que tal modalidade de cuidado materno, mesmo que desafie em certa medida as normas da maternidade, não é capaz de desestabilizar as normas de gênero que estipulam mães biológicas como as cuidadoras principais de suas/eus filhas/os. Assim, suas estratégias de resistência - como a teoria nos informa - são contigentes às regulações culturais e de gênero. 


\section{Considerações finais}

Esta pesquisa explorou as formas pelas quais mulheres brasileiras imigrantes experenciam a maternidade transnacional. Apresentamos os modos pelos quais mulheres nessa situação negociam suas identidades de mães e suas práticas de cuidado materno à distância. Como vimos, o evento migratório é caracterizado por experiências multifacetadas que inauguram novos sentidos e práticas relacionadas à maternidade e ao mesmo tempo reinstauram modelos já vividos.

Por um lado, essas mães podem se sentir inadequadas por não se conformarem às normas convencionais de maternidade. $\mathrm{O}$ peso do mandato acerca da proximidade física na vida de suas/eus filhas/os pode promover sofrimento e sentimentos de inadequação. Muitas vezes suas ocupações como cuidadoras $e$ babás intensificam tais emoções consideravelmente. Por outro lado, como discutido, essas mulheres diversificam e modificam suas noções de cuidado e maternidade com a migração. Seus papéis de geradora de recursos não somente asseguram o bemestar material de suas/eus filhas/os e suas famílias estendidas, mas também diversificam a noção de cuidado. Como descrito, suas próprias experiências como filhas e as tradições de cuidado infantil em suas famílias de origem também têm um papel importante no que se refere às suas concepções de maternidade e práticas de cuidado, as quais se diferenciam substantivamente das normas convencionais. Além disso, o uso das tecnologias e a presença online dessas mães na vida de suas famílias inauguram novas modalidades de cuidado, desafiando, dessa forma, as noções contemporâneas de maternidade e presença.

Discutimos como mães que viviam em contextos pouco favoráveis podem reinventar suas práticas maternas por meio da migração. Elas não somente resistem à pobreza, como, ao mesmo tempo, incluem em seu repertório modos distintos de se relacionar com as normas da maternidade idealizada. Suas narrativas informam que outras racionalidades para além da família nuclear burguesa são possíveis. Essas estratégias não estão desconectadas 
das regulações sociais e morais que organizam a maternidade. No entanto, representam os modos pelos quais essas mulheres puderam articular sua agência em seus contextos de origem, fazendo sentido a suas experiências de migração na conjuntura atual de globalização e intensificação das desigualdades sociais.

\section{Agradecimentos}

Gostaríamos de agradecer o apoio financeiro da Coordenação de Aperfeiçoamento de Pessoal de Nivel Superior (CAPES) para a realização desta pesquisa, pelos comentários de Jeff Miley na preparação deste estudo e pelas observações das/os comentadoras/os anônimas/os dos cadernos pagu.

\section{Referências bibliográficas}

Andersen, Margaret. L.; Collins, Patricia. H. Race, Class, and Gender: An Anthology. California, Wadsworth Cengage Learning, 2012.

BADINTER, Elizabeth. Mother love: myth and reality motherhood in modern history. New York, Macmillan, 1981.

BUTLER, Judith. Undoing gender. New York, Routledge, 2006.

CARPENEDO, Manoela; NARDI, Henrique. Mulheres brasileiras na divisão internacional do trabalho reprodutivo: construindo subjetividades. Revista de Estudios Sociales, Bogotá, (45), 2013, pp.96-109.

Collins, Patricia. Fighting Words: Black Women and the Search for Justice. Minneapolis, University of Minnesota Press, 1998.

DONZELOT, Jacques. The policing of families. New York, Knopf Doubleday Publishing Group, 1979.

DREBY, Joanna. Honor and virtue: Mexican parenting in the transnational context. Gender \& Society $20 \quad$ (1), 2006 [<http://gas.sagepub.com/content/20/1/32.abstract > - acesso em: 1 jun 2015].

DREBY, Joanna. Divided by Borders: Mexican Migrants and Their Children. California, University of California Press, 2010. 
EREL, Umut. Reconceptualizing motherhood: experiences of migrant women from Turkey living in Germany. In: BRYCESON, D.; VUORELA, U. (Eds.). The Transnational Family: New European Frontiers and Global Networks. Cross-Cultural Perspectives on Women. Oxford, Bloomsbury Academic, 2002, pp.62-82.

EVANS, Yara et alii. Brazilians in London: a report for the strangers into citizens campaign. Queen Mary, University of London, London 2007. [<http://www.geog.qmul.ac.uk/globalcities/reports/docs/ brazilians.pdf $>-$ acesso em: 1 jun 2015].

FONSECA, Claudia. Quando cada caso NÃO é um caso: pesquisa etnográfica e educação. Revista Cadernos Cedes, ano 19, n 47 , Caxambu, 1998

[em: $<$ https://poars1982.files.wordpress.com/2008/03/rbde10_06_claudia_fo nseca.pdf $>$ - acesso em: 1 jun 2015].

FONSECA, Claudia. Concepções de família e práticas de intervenção: uma contribuição antropológica. Saúde e Sociedade 14, (2), São Paulo, 2005, pp.50-59.

Foucault, Michel. The subject and power. In DREYFus, H.; RABINOW, P. (Eds.). Michel Foucault: Beyond the Structuralism and Hermeneutics. Chicago University Press, Chicago, 1983, pp.143-168.

FouCAUlt, Michel. The use of pleasure. New York, Vintage Books, 1998.

FOUCAULT, Michel. Ethics: Subjectivity and Truth. In: RaBINOW, P.; HURLEY, R. (Eds.). Essential works of Foucault 1954-1984. New York, New Press, 1997, pp.87-92.

HABERMAS, Jurgen. The Future of Human Nature. Cambridge, Polity Press, 2003.

HIRATA, Helena. A precarização e a divisão internacional e sexual do trabalho. Sociologias, 21, 2009, pp.24-41.

HOCHSCHILD, Arlie. R. Global care chains and emotional surplus value. In: GIDDENS, A.; HutTON, W. (Eds.). On The Edge Living with Global Capitalism. New York, Random House, 2000, pp.130-146.

HoCHSCHILD, Arlie. The Managed Heart: Commercialization of Human Feeling. California, University of California Press, 2003. 
Hondagneu-Sotelo, Pierrete. Doméstica: Immigrant Workers Cleaning and Caring in the Shadows of Affluence. California, University of California Press, 2001.

Hondagneu-Sotelo, Pierrete; Ávila, Ernestine. "I'm here, but I'm there": The Meanings of Latina Transnational Motherhood. Gender \& Society 11 (5), Nova Iorque, Sage, 1997, pp.548-571.

HORTON, Sarah. A mother's heart is weighed down with stones: A phenomenological approach to the experience of transnational motherhood. Culture, Medicine, and Psychiatry 33 (1), Nova Iorque, Springer, 2009, pp.21-40.

Kubal, Angniezka; BAKEWELl, Oliver; De HAAS, Hein. The evolution of Brazilian migration to the uk scoping. Relatório técnico. Oxford, University of Oxford, 2011 [http://www.imi.ox.ac.uk/pdfs/researchprojects-pdfs/ themis-pdfs/THEMIS-scoping-brazil - acesso em: 1 jun 2015].

LOWENKRON, Laura. Consent and vulnerability: some intersections between child sexual abuse and the trafficking in persons for sexual exploitation. cadernos pagu, (45), Campinas, SP, Núcleo de Estudos de Gênero-Pagu/Unicamp, 2015, pp.225-258.

MADIANOU, Mirca. Migration and the accentuated ambivalence of motherhood: the role of icts in filipino transnational families. Global Networks 12 (3), Nova Iorque, Wiley, 2012, pp.277-295.

MADIANOU, Mirca; MILlER, Daniel. Mobile phone parenting: Reconfiguring relation-ships between filipina migrant mothers and their left-behind children. New Media \& Society 13 (3), Nova Iorque, Sage, 2011, pp.457-470.

MADZIVA, Roda; ZoNTINI, Elizabetta. Transnational mothering and forced migration: Un-derstanding the experiences of zimbabwean mothers in the uk. European Journal of Women's Studies 19 (4), Nova Iorque, Sage, 2012, pp.428-443.

MOREIRA, Lisandra Espíndula; NARDI, Henrique Caetano. Mãe é tudo igual? Enunciados produzindo maternidade(s) contemporânea(s). Revista Estudos Feministas 17, (2), Florianópolis, Universidade Federal de Santa Catarina, 2009, pp.569-594.

OAKLEY, Ann. Becoming a mother. New York, Schocken Books, 1979. 
OAKLEY, Ann. Women confined: towards a sociology of childbirth. Nova Iorque, Schocken Books, 1980.

PARRENAS, Rachel. Servants of Globalization: Women, Migration and Domestic Work. California, Stanford University Press, 2001.

PARRENAS, Rachel. Children Of Global Migration: Transnational Families And Gendered Woes. California, Stanford University Press, 2005.

PISCITELli, Adriana. Trânsitos: brasileiras nos mercados transnacionais do sexo. Rio de Janeiro, Eduerj, 2013.

RAJIMAN, Rebeca; SCHMMAH-GESSER, Silvina; KEMP, Adriana. International migration, domestic work, and care work: Undocumented latina migrants in Israel. Gender \& Society 17 (5) Nova Iorque, Sage, 2003 pp.727-749.

RODRíGUES, Encarnacion. The "Hidden Side" of the New Economy: On Transnational Migration, Domestic Work, and Unprecedented Intimacy. Frontiers: A Journal of Women Studies 28 (3), Ohio, Jstor, 2007, pp.60-83.

SASSEN, Saskia. Global cities and survival circuits. In: EHRENREICH, B., HochsCHILD, A. (Eds.). Global Woman: Nannies, Maids, and Sex Workers in the New Economy. Nova Iorque, Henry Holt and Company , 2003, pp.315-334.

SASSEN, Saskia. Two stops in today's new global geographies: Shaping novel labor supplies and employment regimes. American Behavioral Scientist, 52 (3), New York, Sage, 2008, pp.457-496.

SCHMALZBAUER, Leah. Gender on a new frontier: Mexican migration in the rural mountain west. Gender \& Society 23 (6), Nova Iorque, Sage, 2009, pp.747-767.

SMART, Carol. Deconstructing motherhood. Good enough mothering. London, Routledge, 1996.

SuÁREZ-OrOZCO, Carola. The psychosocial experience of immigration. In: SuÁrez-Orozco, C., SuÁrez-OrOzco, M. M. (Eds.). Children of Immigration. The Developing Child. Cambridge MA, Harvard University Press, 2009, pp.68-86.

THERBORN, Goran. Between Sex and Power: Family in the World 1900 2000. Londres, Routledge, 2004. 
Togni, Paula Christofoletti. A Europa é o Cacém: mobilidades, gênero e sexualidade nos deslocamentos de jovens brasileiros para Portugal. Tese (Doutorado em Antropologia Social), Instituto Universitário de Lisboa, 2014.

Zentgraft, Kristina. M.; CHINCHILlA, Norma S. Transnational family separation: A framework for analysis. Journal of Ethnic and Migration Studies 38 (2), Londres, Taylor and Francis, 2012, pp.345-366.

ZIGON, Jarrett. Moral breakdown and the ethical demand: A theoretical framework for an anthropology of moralities. Anthropological Theory, vol. 7(2), 2007, pp.131-150. 